\title{
UNA CONSIDERACIÓN DE LOS FACTORES QUE CONTRIBUYEN AL SUICIDIO INDÍGENA EN GUATEMALA: ESTUDIO DE CASO CUALITATIVO EN NEBAJ, QUICHÉ*
}

\author{
A CONSIDERATION OF THE FACTORS CONTRIBUTING TO INDIGENOUS \\ SUICIDE IN GUATEMALA: QUALITATIVE CASE STUDY IN NEBAJ, QUICHÉ
}

\begin{abstract}
UMA CONSIDERAÇÃO DOS FATORES QUE CONTRIBUEM PARA O SUICÍDIO INDÍGENA NA GUATEMALA: ESTUDO DE CASO QUALITATIVO EM NEBAJ, QUICHÉ
\end{abstract}

Wayne J. Pitts

Ph.D. en Sociology de University of New Mexico. RTI International, Estados Unidos wpitts@rti.org | https://orcid.org/oooo-0oo3-4428-2356

Christopher S. Inkpen $\mathrm{PhD}$ en Sociología y Demografía de Penn State University. RTI International, Estados Unidos cinkpen@rti.org | https://orcid.org/oooo-0001-9609-0220

Renata Zablocka
Master of Arts (MA) en Psicología Forense de John Jay College of Criminal Justice. RTI International, Estados Unidos
rzablocka@rti.org | https://orcid.org/o000-0002-0097-8709

Pamela K. Lattimore

PhD en Economía de University of North Carolina. RTI International, Estados Unidos lattimore@rti.org | https://orcid.org/oooo-0o01-9870-8258

\begin{abstract}
Fecha de recepción: 11 de mayo de 2021 Fecha de aceptación: 30 de julio de 2021 Disponible en línea: 1 de septiembre de 2021
\end{abstract}

Sugerencia de citación: Pitts, W.J., Inkpen, C.S., Zablocka, R. y Lattimore, P. K. (2022). Una consideración de los factores que contribuyen al suicidio indígena en Guatemala: estudio de caso cualitativo en Nebaj, Quiché. Razón Crítica, 12. https://doi.org/10.21789/25007807.1804

\section{Resumen}

Antecedentes: El municipio guatemalteco de Nebaj es una comunidad indígena maya con tasas de suicidio percibidas como superiores al promedio nacional. Objetivos: Este artículo evalúa las percepciones de los factores relacionados con el suicidio en Nebaj para informar las estrategias de prevención frente a este. Métodos: Esta investigación utiliza métodos cualitativos y cuantitativos. Los datos provienen de 19 entrevistas semiestructuradas con partes interesadas en Nebaj, junto con revisiones de casos de registros administrativos oficiales de la Policía Nacional Civil (PNC) y estadísticas agregadas de registros oficiales de suicidios recopilados por

\footnotetext{
* Esta investigación fue financiada por el Departamento de Estado de los Estados Unidos, Sección Antinarcóticos y Asuntos de la Ley (INL por sus siglas en inglés). El contenido es responsabilidad exclusiva de los autores y no necesariamente representa las opiniones oficiales de INL o el Departamento de Estado de los EE. UU.
} 
la PNC y el hospital de Nebaj. Resultados: Las partes interesadas locales vinculan el suicidio con deudas pendientes, la disolución de relaciones románticas, problemas de salud mental, conflictos intrafamiliares y abuso de sustancias. A nivel comunitario, los entrevistados relacionan la disolución de familias a través de la migración y las deudas resultantes. Limitaciones: Las instituciones públicas que abordan el suicidio están aisladas y no trabajan juntas ni recopilan datos con los mismos fines. Los datos disponibles están fragmentados y son difíciles de contrastar entre fuentes. Conclusión: Las entrevistas revelan temas comunes en la percepción de factores contribuyentes al suicidio en Nebaj. Los datos empíricos muestran que es más probable que los jóvenes participen en intentos de suicidio fatales y no fatales. Los análisis también indican que el método de suicidio más común es la ingestión de pesticidas agrícolas.

Palabras clave: Nebaj; Guatemala; suicidio indígena.

\section{Abstract}

The Guatemalan municipality of Nebaj is an indigenous Mayan community with higher suicide rates than the national average. This article evaluates the perceptions of factors related to suicide in Nebaj in order to suggest prevention strategies against this phenomenon. The research applies qualitative and quantitative methods, collecting data through 19 semistructured interviews with different stakeholders, along with case reviews of official administrative records of the National Civil Police (PNC) and aggregated statistics of official suicide records collected by this institution and Nebaj's local hospital. Participant stakeholders link suicide with money debts, the dissolution of romantic relationships, mental health problems, intra-family conflicts, and substance abuse. At the community level, interviewees relate the dissolution of families due to migration reasons and the resulting debts of this process as the main motivations for suicide. Evidence shows that public institutions in charge of addressing this phenomenon work independently and do not collect data cooperatively for the same purposes. Hence, one of the limitations of this study is that the available data is fragmented and difficult to contrast among sources. Despite this, findings reveal common issues in the perception of factors contributing to suicide in Nebaj. Additionally, empirical data shows that young people are more likely to participate in fatal and non-fatal suicide attempts and that the most common method is the intake of agricultural pesticides.

Keywords: Nebaj; Guatemala; indigenous suicide.

\section{Resumo}

O município guatemalteco de Nebaj é uma comunidade indígena maia com taxas de suicídio percebidas como superiores à média nacional. Neste artigo, são avaliadas as percepções dos fatores relacionados com o suicídio em Nebaj para informar as estratégias de prevenção diante deste. Esta pesquisa utiliza métodos qualitativos e quantitativos. Os dados provêm de 19 entrevistas semiestruturadas com partes interessadas em Nebaj, junto com revisões de casos de registros administrativos oficiais da Polícia Nacional Civil (PNC) e estatísticas incorporadas de registros oficiais de suicídios recopilados pela PNC e pelo hospital de Nebaj. As partes interessadas locais vinculam o suicídio com dívidas pendentes, a dissolução de relações românticas, os problemas de saúde mental, os conflitos intrafamiliares e o abuso de substâncias. No âmbito comunitário, os entrevistados relacionam a dissolução de famílias por meio da migração e das dívidas resultantes. As instituições públicas que abordam o suicídio 
estão isoladas e não trabalham juntas nem coletam dados com os mesmos objetivos. Os dados disponíveis estão fragmentados e são difíceis de contrastar entre fontes. As entrevistas revelam temas comuns na percepção de fatores contribuintes para o suicídio em Nebaj. Os dados empíricos mostram que é mais provável que os jovens participem de tentativas de suicídio fatais e não fatais. As análises também indicam que o método de suicídio mais comum é a ingesta de pesticidas agrícolas.

Palavras-chave: Nebaj; Guatemala; suicídio indígena.

\section{Contexto y antecedentes breves de Nebaj}

Guatemala se ubica como un país de ingresos medianos bajos en términos de PIB per cápita, pero es muy desigual. El quintil superior de la población recibe el 57,3\% del ingreso familiar per cápita (PNUD, 2016, p. 41). Tradicionalmente, esto ha significado la concentración del poder económico en manos de un número relativamente pequeño de familias de élite. La desigualdad en Guatemala también está estrechamente relacionada con la etnia. Aproximadamente la mitad de la población son mayas, hablan una de las 23 lenguas indígenas y, según se mida (ingresos, salud, educación), los mayas rurales son los más desfavorecidos de Guatemala. Según la UNPD, el 86,6 \% de la población indígena vive en la pobreza, en comparación con el 53,9 \% de la población no indígena (Bell, 2017; PNUD, 2016). Santa María Nebaj (Nebaj) es un municipio guatemalteco en el departamento del Quiché en la región Ixil Maya con una población estimada de 72.686 personas, de las cuales 31.935 viven en el área urbana y 40,751 en el área rural (Censo, 2019). La región del altiplano occidental incluye áreas al oeste de la ciudad de Antigua Guatemala. Más de la mitad de la población en el altiplano occidental son pueblos indígenas de ascendencia maya. Actualmente, esta región se caracteriza por una infraestructura débil del gobierno central, pobreza intensa y conflictos sociales y discriminación étnica, que ha contribuido al subdesarrollo.

Cualquier consideración de Nebaj y las comunidades rurales mayas circundantes estaría incompleta sin tener en cuenta el contexto histórico de colonización y violencia racializada. La colonización española de las Américas comenzó en la tierra del siglo XVI y, durante los siguientes 200 años, el virreinato colonial de la Nueva España expropió los territorios mayas que ahora incluyen gran parte de los países modernos de México, Guatemala, Belice, Honduras y El Salvador. Los estudiosos decoloniales han demostrado cómo los conquistadores españoles impusieron un sistema de jerarquías raciales coloniales para justificar la violencia y relegaron a los pueblos mayas dentro de un marco de "no ser" (Fanon, 1967; 1968). Basada en políticas de expropiación y privatización de tierras, la rígida estructura social colonial facilitó la propiedad de tierra de las élites sociales españolas a expensas de los pueblos indígenas. En 1821, Guatemala se independizó de España y, a finales del siglo XIX y principios del Xx, el peonaje por deudas floreció, especialmente entre los mayas rurales, como consecuencia de la rápida expansión de la demanda de materias primas en el Norte Global (McCreery, 1983). Además, el potencial de explotación agrícola atrajo a varias empresas extranjeras, como la United Fruit Company. Estas empresas fueron apoyadas por los gobernantes autoritarios del país y el Gobierno de los Estados Unidos a través de las brutales regulaciones laborales y concesiones masivas a los terratenientes ricos (Bucheli, 2008). 
La inestabilidad política y social que se intensificó después de que un golpe patrocinado por Estados Unidos derrocó a un gobierno elegido democráticamente se convirtió en una violencia civil que inició en 1960 y duró 36 años. Murieron más de 200.00o guatemaltecos y otros 45.00o desaparecieron y, en su momento más intenso en las décadas de 1970 y 1980, apuntó a las comunidades mayas en un esfuerzo por erradicar las bases potenciales de apoyo a los rebeldes marxistas (Carmack, 1988; Manz, 2004; Nolin, 2018). Aproximadamente el 93 \% de los asesinatos, desapariciones y otras atrocidades fueron cometidas por el ejército y sus fuerzas de seguridad paramilitares (Rothenberg, 2012).

Aunque los Acuerdos de Paz de las Naciones Unidas se firmaron en 1999, la impunidad, la violencia, las prácticas judiciales contrapuestas y la naturaleza del Estado guatemalteco en la posguerra continúan planteando serios desafíos para los pueblos mayas. Las nociones de modernidad e identidad nacional a menudo se entrelazaban con un sentido de colonialidad que excluía sistemáticamente las identidades étnicas indígenas del discurso nacional y servía para relegar a los pueblos indígenas a los márgenes de la sociedad. Los efectos acumulativos e intergeneracionales de la violencia, la discriminación, el malestar político y la marginación económica experimentados por los pueblos mayas en Guatemala pueden mapearse directamente en la salud mental indígena. Más del 25 \% (3.250.000 personas) de la población sufrirá algún trastorno mental en su vida, pero menos del $1 \%$ de los gastos en atención de salud del Ministerio de Salud están destinados a la salud mental (Klie \& Grazioso, 2020).

A pesar de que la información pública sobre suicidios consumados o intentos de suicidio en la región es limitada, la evidencia anecdótica indica que el suicidio es mucho más frecuente que la tasa nacional de 2,74 por cada 100.000 personas. Por ejemplo, algunos informes indican 40 intentos de suicidio y 10 suicidios consumados en 2017, lo que puede considerarse una tasa alta de suicidios para una población pequeña. Estas anécdotas son lo que estimuló nuestro interés en aprender más sobre este fenómeno en la región maya Ixil, enfocada en Nebaj, Quiché. Según los últimos datos de la Organización Mundial de la Salud (OMS) publicados en 2018, las muertes por suicidio en Guatemala fueron 448 o o,63 \% del total de muertes (World Life Expectancy, 2021). 
Figura 1. Municipio de Nebaj, departamento de Quiché

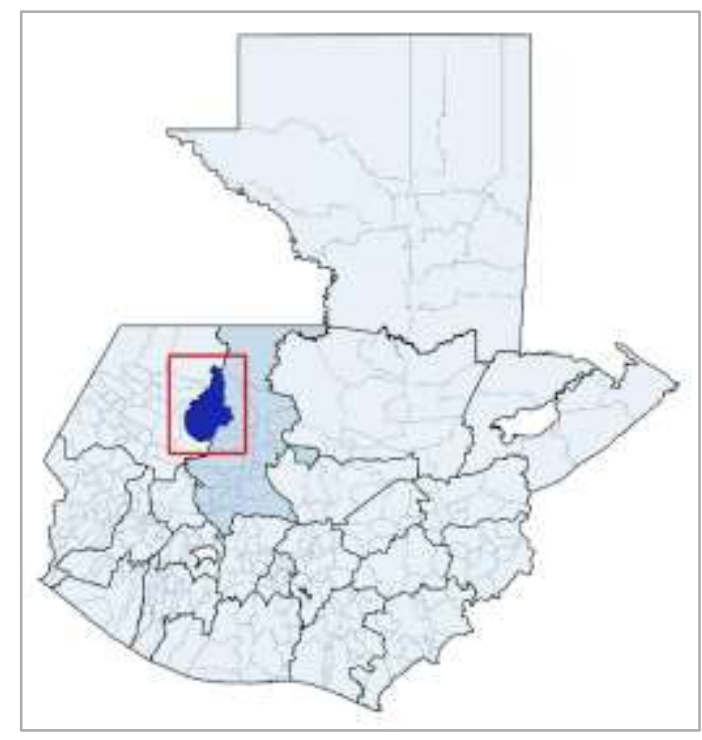

Fuente: Elaboración propia usando QGIS.

Según la Organización Mundial de la Salud, aproximadamente 800.00o personas mueren anualmente debido al suicidio (OMS, 2014). América Latina, que tiene tasas de suicidio por debajo de la incidencia mundial, tiene alrededor de 65.000 suicidios por año (OPS, 2014). Este estudio tiene la intención de explorar la incidencia y las razones del suicidio en los indígenas, principalmente en la región Ixil del altiplano occidental en el departamento guatemalteco de El Quiché, centrándose en y alrededor del municipio de Nebaj. El estudio exploratorio examinó los factores que impulsan a las personas a participar en comportamientos suicidas, los servicios disponibles y las barreras para recibir servicios y otro tipo de apoyo. Una comprensión más profunda de los factores asociados con el comportamiento suicida en Nebaj orientará los esfuerzos futuros para explorar la prevención y las reacciones al suicidio en esta región, así como los esfuerzos futuros de recopilación de datos.

El comportamiento suicida incluye autolesiones deliberadas y actos suicidas (Anderson et al., 2012). Se han identificado varios factores que contribuyen al comportamiento suicida en la bibliografía de psicoterapia convencional, incluidos los antecedentes familiares de suicidio (Rajalin \& Salander Renberg, 2017); separación de los padres, divorcio y matrimonios nuevos (Haimi \& Lerner, 2016; Lizardi et al., 2010; Rubenstein et al., 1998); déficits en la resolución de problemas (Chu et al., 2018); impulsividad (Klonsky \& May, 2015); sentimientos de desesperanza y depresión (Jaiswal et al., 2016; Stack \& Scourfield, 2013); ira y hostilidad (Ammerman_et al., 2016); trastornos psiquiátricos (Turecki \& Brent, 2016); noticias en los medios de comunicación (Mueller, 2017); suicidio de compañeros (Rogers \& Joiner, 2018); abuso de sustancias (Reed, Nugent \& Cooper, 2015); y acoso (bullying) (Goldblum et al., 2015). Sin embargo, los contextos sociales y culturales (por ejemplo, diferentes precipitantes, factores de vulnerabilidad y protección, y reacciones a comportamientos suicidas), en la región de enfoque, son distintos de las áreas donde se realizó gran parte de esta investigación. 
La prevalencia del suicidio en la región ixil ha recibido cobertura por parte de la prensa guatemalteca a nivel local y nacional, lo que representó un indicador adicional para que nuestro equipo realizara esta revisión exploratoria de la situación en la región. Se han publicado varios artículos periodísticos que abordan el suicidio en el municipio de Nebaj y las comunidades cercanas (Barreno Castillo, 2018; Cordero, 2018, 2019; ImpactoGT, 2018). Estos artículos señalan una serie de posibles factores responsables de influir en la incidencia del comportamiento suicida por encima del promedio en Nebaj. Los efectos psicológicos, resultado de la guerra civil de 36 años, incluyen depresión, ansiedad y estrés postraumático; efectos de segunda generación sobre la salud mental que afectan a los niños de aquellos que vivieron la guerra; consumo de alcohol y drogas, especialmente inhalantes; desintegración familiar y falta de habilidades parentales; respuestas débiles por parte del Gobierno para abordar los problemas de salud pública; pocos profesionales de salud mental calificados para abordar los problemas; facilidad de acceso a los pesticidas, a menudo utilizados para suicidarse; emigración a los Estados Unidos y la erosión asociada de los sistemas de apoyo familiar; una persistente falta de oportunidades económicas; peleas entre amantes; violencia intrafamiliar; abandono escolar y falta de actividades sociales y comunitarias para los jóvenes; y ciberacoso. La falta de claridad y de conocimientos sobre el suicidio en esta región es una razón muy probable por la cual muchos casos suicidas no se reportan. Un estudio de diecisiete años sobre la muerte por intención indeterminada y accidentes por envenenamiento/asfixia con pesticidas en Taiwán mostró que las tasas reales de suicidio pueden subestimarse en más del $30 \%$ (Chang et al., 2010).

Una de las publicaciones de Prensa Libre, del 23 de septiembre de 2018, proporciona estadísticas de suicidios consumados que se obtuvieron de la clínica de psicología de la Clínica de Salud Pública Ixil desde 2009 hasta agosto de 2018. De ellos, el más bajo fue en 2009 (6 casos) y el más alto en 2013 (25 casos) (Barreno Castillo, 2018) (Tabla 1). El artículo establece que la tasa de suicidios en la región había sido una preocupación de las autoridades sanitarias y municipales durante los últimos 10 años. Enumera específicamente a la guerra y el uso de alcohol y drogas como los principales contribuyentes a la situación actual. El envenenamiento por el consumo de pesticidas se indica como el método más común de suicidio, seguido del ahorcamiento. Si bien se sabe poco sobre los factores que influyen en los métodos de suicidio, las normas socioculturales son un componente importante de este proceso de decisión. La investigación sobre intentos de suicidio y los factores que influyen en los métodos de suicidio muestra que los sujetos preferían las estrategias "más rápidas y fáciles" (Biddle et al., 2010). 
Figura 2. Número de casos de suicidio en Nebaj desde los años 2009 - agosto de 2018

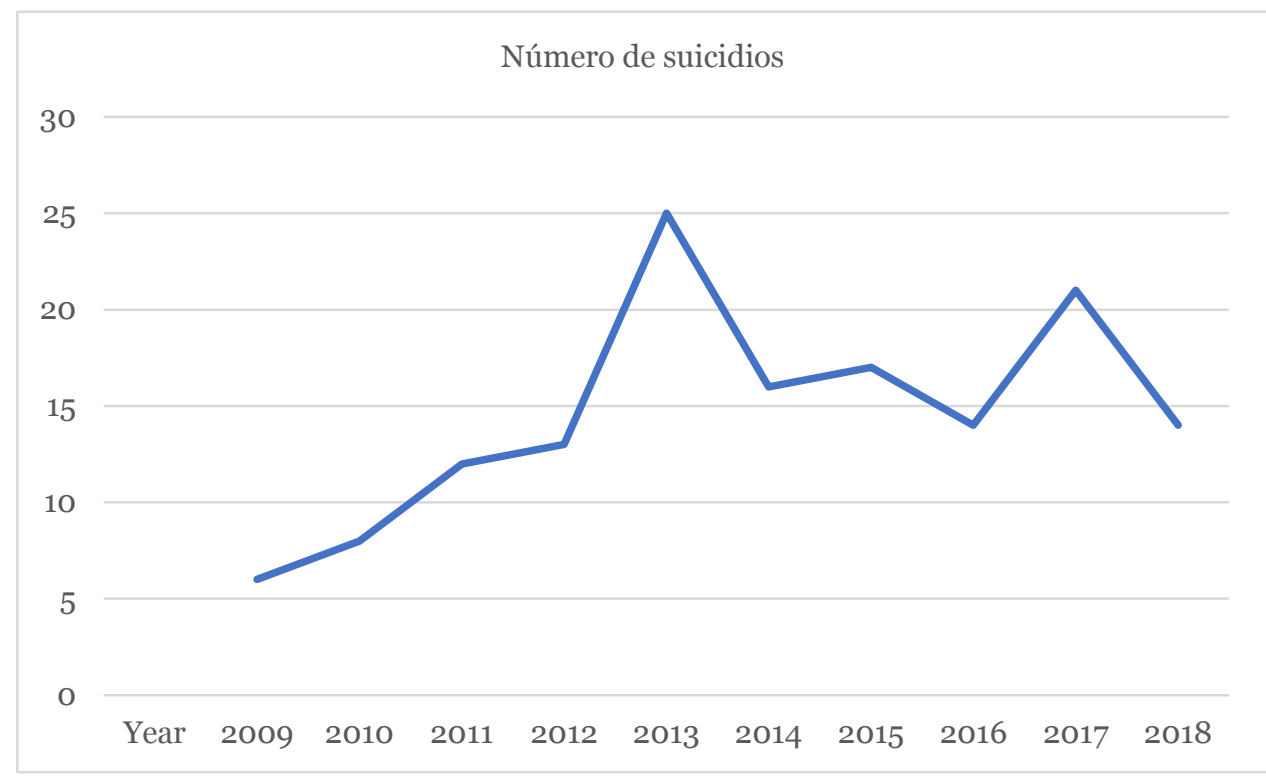

Fuente: Clínica de Psicología del Área de Salud Ixil, según lo citado por el artículo de Prensa Libre del 23 de septiembre de 2018.

Otra publicación de Prensa Libre del 20 de mayo de 2019 reportó 41 casos de suicidio en la región Ixil en 2018. Algunos de ellos no se presentaron a las autoridades como suicidios, sino como una muerte por una enfermedad común (Cordero, 2019). Estos casos se registraron como parte de un estudio realizado por el departamento de psicología del Área de Salud del Quiché. El estudio determinó que la desintegración familiar, debido a la migración a los Estados Unidos, es la causa principal del suicidio. Muchos padres abandonan Guatemala debido a la falta de trabajo en los municipios locales y dejan a sus hijos con abuelos $\mathrm{u}$ otros familiares, lo que expone a los niños a sustancias, falta de oportunidades y pobreza. El artículo manifestó la preocupación de que, a pesar de las 41 muertes registradas el año pasado en la región Ixil, ninguna de las instituciones del gobierno local ha implementado algún plan para prevenir estos hechos.

Hay escasez de investigaciones publicadas sobre suicidio indígena, quizás porque estos grupos son a menudo grupos minoritarios marginados. De manera similar, los trastornos de salud mental en grupos indígenas latinoamericanos no se han estudiado a profundidad (Azuero et al., 2017).

\section{Métodos y muestra}

Este estudio utilizó una combinación de métodos exploratorios cuantitativos y cualitativos para responder las preguntas de la investigación. Específicamente, el análisis se basó en 19 entrevistas semiestructuradas con partes interesadas relevantes en Nebaj. Además de estas entrevistas, el estudio también incorporó revisiones de casos de registros administrativos oficiales del hospital de Nebaj y de la Policía Nacional Civil (PNC), junto con 
estadísticas agregadas de los registros oficiales de defunción recopilados por la PNC en Nebaj. Este enfoque de métodos múltiples permitió un análisis exhaustivo de las percepciones de suicidio en el área, al tiempo que proporcionó una imagen empírica limitada del suicidio en Nebaj.

La investigación del suicidio es importante, pero plantea varios desafíos éticos (Gibson, Benson \& Brand, 2012). Se ha demostrado que las personas vulnerables que previamente han tenido comportamientos suicidas a menudo experimentan angustia y una mayor ideación suicida después de participar en estudios de investigación, aunque esta angustia se ve compensada por el deseo de participar en la actividad y los beneficios terapéuticos de una investigación bien realizada (Biddle et al., 2013). Dado que los sobrevivientes de intentos de suicidio y los familiares de quienes se han suicidado son poblaciones vulnerables, este estudio busca comprender el suicidio en Nebaj por medio de entrevistas a profesionales que trabajan en sectores relevantes, como la salud pública, el gobierno municipal y los servicios para jóvenes.

Se crearon dos guías de entrevista, una para proveedores de servicios directos (por ejemplo, psicólogos, funcionarios de salud, etc.) y otra para otros actores clave que pueden proporcionar una perspectiva importante sobre las circunstancias locales, a pesar de que no estén prestando servicios directamente. Ambas versiones del protocolo se centraron en los siguientes factores: (1) la percepción del suicidio del encuestado y los problemas relacionados en la región, (2) factores que impulsan a las personas a suicidarse, (3) tipos de servicios y apoyo disponibles para las personas que están en riesgo de suicidio, (4) barreras para acceder a estos servicios/apoyo y por último (5) recomendaciones para acciones futuras. Además de estas preguntas, la versión para proveedores de servicios directos preguntó sobre su propio papel y el papel de sus organizaciones en la prestación de servicios a la población afectada. Ambos protocolos incluyeron preguntas demográficas generales y preguntas específicas sobre la experiencia educativa y profesional del encuestado, y terminaron con una pregunta sobre qué otros actores clave relevantes deberían ser invitados a participar en el estudio. Los protocolos de la entrevista fueron probados internamente tanto en inglés como en español por expertos en análisis, para mejorar el desempeño en el campo.

Las revisiones de casos administrativos exploraron los datos demográficos de los individuos suicidas y las circunstancias que rodean los intentos de suicidio y los suicidios consumados (por ejemplo, método de intento/suicidio consumado, razones dadas para el intento/consumar el suicidio). El reclutamiento en el campo y las entrevistas fueron realizadas por una consultora local y un investigador cualitativo no afiliado que coordinó los esfuerzos de recolección de datos en Nebaj siguiendo los procedimientos internos. ${ }^{1}$ La consultora fue una mujer maya k'iche que vive y trabaja en la región del altiplano occidental de Guatemala y tiene un amplio conocimiento del contexto local. Los investigadores realizaron tres capacitaciones con la consultora en el campo: sobre estrategias de reclutamiento, protocolos de entrevistas y recolección de datos.

${ }^{1}$ La Junta de Revisión Institucional de RTI revisó el protocolo de estudio y determinó que no se trata de investigación con sujetos humanos. Formularios de consentimiento para participar en el estudio fueron elaborados, traducidos al español y revisados y firmados antes de cada entrevista. 
A lo largo de este estudio, los investigadores se contactaron con tres entidades locales para solicitar acceso a archivos administrativos desidentificados para su revisión: un hospital local, la oficina del Ministerio de Salud Pública del distrito y la sede distrital de la PNC. El hospital local en Nebaj acordó proporcionar datos agregados en lugar de dar acceso a los archivos. Se recibieron hojas de cálculo del departamento de estadística del hospital, que enumeran 129 intentos e incidentes de suicidios consumados entre 2016 y 2018. La PNC otorgó acceso limitado a registros administrativos y se completaron revisiones de casos para 27 suicidios consumados documentados entre 2016 y 2018.

Este estudio busca presentar perspectivas sobre el suicidio en Nebaj por parte de funcionarios y partes interesadas que trabajan en campos relevantes o que pueden proporcionar información de la comunidad. Como tal, los participantes del estudio fueron reclutados de las reuniones municipales con la aprobación de los funcionarios municipales locales. El estudio fue presentado a la comunidad local relevante durante dos reuniones de la Comisión Municipal para la Prevención de la Violencia en noviembre de 2018. Asistieron a las reuniones las partes interesadas de la comunidad, los funcionarios públicos y las fuerzas del orden local. Estas reuniones también marcaron el primer esfuerzo de reclutamiento del estudio: los asistentes fueron invitados a programar entrevistas y proporcionaron materiales de consentimiento para el estudio. Para aumentar el tamaño de la muestra relevante a través del muestreo dirigido por los encuestados, una vez que comenzó la recopilación de entrevistas, se pidió a cada participante que identificara a otros posibles encuestados y proporcionara su información de contacto para la divulgación del reclutamiento.

La muestra para este estudio constó de 22 adultos que viven o trabajan en Nebaj. El 23 \% de la muestra se dedicaba al Trabajo Social, el área de empleo más común, en comparación con los siguientes dos campos más comunes: Psicología y gobierno municipal, ambos con el $18 \%$ de la muestra. El $14 \%$ de la muestra trabajaba en salud pública, seguido de religión (9\%), aplicación de la ley (9\%) y otras áreas (10 \%). Demográficamente, el 68 \% de la muestra fueron hombres, con una edad promedio de 41 años, para aquellos que revelaron su edad. De los que compartieron su origen étnico, el $85 \%$ se identificaron como mayas, de los cuales el $95 \%$ se identificaron como ixil. Los comentarios individuales de los profesionales entrevistados no se especifican en la discusión a continuación para proteger su identidad.

Se completaron 19 entrevistas con los 22 encuestados (a 1 entrevista asistieron 4 entrevistados). La recolección de datos se realizó entre el 14 de noviembre y el 6 de diciembre del 2018. Todas las entrevistas fueron grabadas digitalmente, transcritas en español y luego traducidas del español al inglés. La duración de las entrevistas varió de 29 a 83 minutos, con una duración promedio de 52 minutos. Una vez traducidas al inglés, se utilizó el software de evaluación de calidad de datos de rutina (RDQA) para el análisis cualitativo de datos.

En ese sentido, este estudio empleó un libro de códigos desarrollado en parte a partir de las preguntas de la investigación, y en parte a partir de un enfoque de teoría fundamentada. Este último implica dejar que los temas emerjan del texto y clasificarlos en una agrupación y jerarquía natural (Gilgun, 2009; Glaser, 1992). Además, las entrevistas fueron codificadas y 
revisadas por el personal del proyecto. Los resultados más destacados se presentan en la sección de resultados de esta investigación.

\section{Diseño de la investigación y resultados}

Esta sección describe los resultados de la codificación cualitativa de las 19 entrevistas. En casi todos los casos, la descripción de los códigos relevantes solo se incluía si los temas estaban presentes en al menos cinco entrevistas. Los resultados presentados tienen como objetivo responder las siguientes preguntas: (1) ¿Cuál es la prevalencia del suicidio en Nebaj? (2) ¿Cuáles son los factores individuales, (3) familiares y (4) a nivel comunitario asociados con el suicidio? (5) ¿Cómo interactúan estos factores? Y, por último, (6) ¿qué se puede hacer para prevenir el suicidio?

\section{¿Cuál es la prevalencia del suicidio en Nebaj?}

La pregunta de qué tan común es el suicidio en Nebaj es difícil de responder, principalmente porque los intentos de suicidio o los suicidios consumados no se miden ni documentan sistemáticamente en Nebaj. Una de las cuestiones que afectan a la cuantificación es que no existe una forma común o método acordado para designar que ocurrió un intento de suicidio o un suicidio consumado. Reflexionando sobre esto, uno de los encuestados dijo: "No existe una herramienta estandarizada para todas las instituciones, por ejemplo. Si detecto un riesgo de suicidio, lo registro. No hay un método estándar" (Psicólogo, entrevista personal).

A pesar de que pocos de los participantes tenían estadísticas a la mano, muchos lo consideraron como algo común. Más de la mitad de los entrevistados mencionaron que el suicidio es común, aceptado o, incluso, va en aumento. Un psicólogo enmarcó el tema del suicidio como una opción aceptable al decir que "[...] ya lo consideran una práctica [...]" y eso "[...] en su inconsciente lo ven como otra opción, y es común para las personas... Lo ven como otra opción para resolver sus problemas [...]" (Psicólogo, entrevista personal, 6 de diciembre de 2018). Como lo indica la siguiente cita, los participantes en Nebaj tienden a estar de acuerdo con que la práctica del suicidio se ha convertido en algo común:“... Es común, común; la gente ya lo ve así. Pero de hecho es una situación que nos preocupa mucho, a pesar de que es difícil de aceptar" (Trabajadora social, entrevista personal, 27 de noviembre de 2018).

Algunos entrevistados señalaron que los suicidios en Nebaj parecieran estar vinculados o inspirados en un suicidio inicial, como un brote que ocurre en destellos. Ciertos encuestados retrataron el fenómeno del suicidio como "una ola", lo que sugiere que, "sucede sucesivamente. No en la misma familia o algo, sino en casos individuales que ocurren en una ola". Las partes interesadas compararon la ocurrencia del suicidio con "una enfermedad que podría ser contagiosa”. Al describir la aparente conexión de los suicidios, un psicólogo señaló lo siguiente: "Es común, pero es una especie de epidemia: el suicidio es episódico. En otras palabras, a veces es como un 'boom”' (Psicóloga del Juzgado, entrevista personal, 28 de noviembre de 2018). Otros entrevistados dijeron que "hay una ocurrencia constante de suicidios".

En respuesta a preguntas sobre la prevalencia del suicidio, 4 de 19 partes interesadas sugirieron que las tasas de suicidio han aumentado con el tiempo. En comparación con los 
municipios circundantes, algunas partes interesadas indicaron que Nebaj es un caso atípico: "Cubrimos 7 municipios y Nebaj es el único que reporta una gran cantidad de suicidios" (Funcionario del Ministerio Público - Oficina de Atención a la Víctima, entrevista personal, 6 de diciembre de 2018).

Si bien se está de acuerdo, entre los miembros de la comunidad, con que el suicidio se acepta como algo común en Nebaj, existe cierto debate sobre si los suicidios están aumentando, disminuyendo o si han permanecido estáticos. Un inspector de la policía indicó que los suicidios, que ocurrían casi a diario, han disminuido. Afirmó: "He sido testigo de que ha bajado. Repito: en el pasado era entre dos, uno o dos por día. Ahora, gracias a Dios, puedo decirle que es uno cada dos semanas, tres semanas" (Inspector de policía, entrevista personal, el 15 de noviembre de 2018).

Estos hallazgos sugieren que, a pesar de que las personas en Nebaj son muy conscientes respecto del suicidio, la falta de datos sistemáticamente recopilados y disponibles al público conducen a nociones competitivas de cuán común es el problema y si está creciendo o disminuyendo.

\section{¿Cuáles son los factores a nivel individual que motivan el suicidio?}

Las causas del suicidio en Nebaj son numerosas y complejas; pocos encuestados mencionan solo una posible causa. Esta sección presenta las respuestas que dieron los entrevistados cuando se les pidió que describieran las causas o los factores que motivan el suicidio en Nebaj. De igual manera, describe las explicaciones más comúnmente referenciadas para el suicidio dentro del municipio, incluidas las causas/factores que se mencionaron en al menos cinco entrevistas.

\section{Problemas de relación (11 entrevistas)}

La mayoría de los interesados tendieron a estar de acuerdo en que las relaciones individuales y su disolución pueden estar vinculadas al suicidio en Nebaj, especialmente para los jóvenes. Más de la mitad de los entrevistados indicaron que los problemas con sus parejas eran una posible justificación, si no la principal. De igual modo, dijeron que el suicidio puede ser una respuesta a "un problema relacionado con temas del corazón". Asimismo, señalaron la importancia de las rupturas o separaciones, también vinculadas con "infidelidad dentro del matrimonio". Al describir las motivaciones para el suicidio en Nebaj, un trabajador social señaló la importancia de la disolución de una relación: "Esa es la más común que conozco porque he preguntado por ahí: rupturas amorosas” (Trabajadora social, entrevista personal, el 27 de noviembre de 2018).

Esta explicación parece ser más relevante para la juventud. Más de una cuarta parte de los encuestados reconoció a los problemas amorosos como causas del suicidio entre jóvenes o adolescentes. Al describir el problema, otro trabajador social explicó:

La causa principal entre los jóvenes y los adolescentes son las rupturas amorosas. La joven se suicida cuando el joven la deja y viceversa, ¿̇verdad? Hemos descubierto que es la razón número uno entre los jóvenes (Trabajador social, entrevista personal, 27 de noviembre de 2018). 
Los participantes también señalaron que muchos jóvenes buscan pareja para que les proporcionen lo que no pueden encontrar en su propia familia. Al describir un escenario de una adolescente que intentó suicidarse, un psicólogo dijo lo siguiente:

\footnotetext{
Ella dijo que no podía superar a su novio. Entonces, creo que muchas cosas comienzan a acumularse, porque esperan encontrar en sus parejas lo que no pueden encontrar en casa. Y, si tampoco lo encuentran con sus parejas, entonces se sienten frustrados (Psicólogo, entrevista personal, 6 de diciembre de 2018).
}

Los entrevistados señalaron que, aunque los problemas de relaciones amorosas pueden no ser el único factor, el estrés de las relaciones fallidas, especialmente para los jóvenes de la región, es un factor que contribuye a la ideación suicida.

\section{Falta de oportunidades económicas (6 entrevistas)}

Los trabajos, o la falta de ellos, también se mencionaron como una posible motivación para el suicidio. Sin embargo, en contraste con los problemas de relación -que los encuestados identificaron más rápidamente como una causa directa-, la falta de trabajo representó una explicación más abstracta para los encuestados: "no hay trabajos, no hay ingresos". Casi uno de cada tres encuestados indicó que la falta de oportunidades de empleo, aunque quizás no sea el factor principal, desempeña un papel en la motivación del suicidio. Según lo descrito por un psicólogo, la falta de trabajo puede desempeñar un papel en el avance hacia el comportamiento suicida:

Siento que la falta de empleo también es una de las causas. Porque el suicidio no es algo en lo que piensen hoy y se suiciden al día siguiente. Es más bien una serie de cosas que afectan a las personas gradualmente (Psicólogo, entrevista personal, 6 de diciembre de 2018).

Un participante mencionó que la falta de empleos, junto con los gastos diarios, puede tener un efecto: "Hay mucha desesperación porque no hay empleo, no lo hay. El alto costo de vida también” (Empleada de la Asociación Indígena - Red de Mujeres Ixiles, entrevista personal, 6 de diciembre de 2018).

Además, los encuestados que indicaron que la falta de trabajo puede ser una explicación para el suicidio, también sugirieron que esto está relacionado con un sentimiento general de estancamiento o de no sentirse útil. Un trabajador social lo describió de la siguiente manera:

No hay empleo. Si encuentras uno, la paga es miserable, y, esa es la debilidad del Gobierno, no pueden cumplir con sus obligaciones. No hay planes de desarrollo, para generar ingresos, para que las personas se sientan útiles con sus trabajos, para que se sientan parte de un desarrollo económico productivo (Trabajador social, entrevista personal, 20 de noviembre de 2018).

Estas respuestas muestran cómo las personas vinculan las fuerzas estructurales del estancamiento económico con un papel en la decisión de intentar suicidarse. Aunque esto no es 
una motivación tan aparente como el deterioro de las relaciones personales, la falta de trabajo parece ser un factor destacado en la discusión sobre el suicidio en Nebaj.

\section{Imitar a otros / llamar la atención (6 entrevistas)}

Los encuestados también señalaron el impacto de un suicidio dentro de una familia o grupo de amigos de tener un efecto de contagio o de estimular a otros a imitar a alguien que intentó o se suicidó. Aunque ninguno de los encuestados destacó el "copiar a otros" como un factor principal para explicar el fenómeno del suicidio en Nebaj, seis de los diecinueve participantes mencionaron casos de copia o mimetismo

\section{Deudas pendientes (6 entrevistas)}

Alrededor de un tercio de los encuestados señalaron las deudas como otra explicación, aparte de la falta de trabajo y la pobreza. Específicamente, para los participantes que mencionaron las deudas, la describieron como un "shock cuando sus casas u otras pertenencias son embargadas por el banco". Las deudas, según lo descrito por un encuestado, son una fuente de tensión que lleva a las personas a suicidarse: "Hay personas que deben una cantidad y ya no son capaces de pagar esa deuda. Luego, toman esa decisión” (Oficial de policía, entrevista personal, 14 de noviembre de 2018).

Las partes interesadas describieron las tasas de interés cambiantes en las cooperativas y los bancos como una fuente de estrés para las personas en Nebaj y un posible factor de motivación en los suicidios, aunque esto se asocia más comúnmente con los adultos que con los jóvenes.

\section{Angustia emocional (8 entrevistas)}

Los encuestados también se apresuraron a sugerir que los jóvenes y adultos que intentan suicidarse están luchando para manejar sus emociones, se sienten frustrados debido a una acumulación de problemas o están lidiando con problemas específicos de salud mental. Específicamente, dos psicólogos entrevistados en el estudio indicaron que la baja autoestima era un tema común para quienes intentaron o se suicidaron: "La autoestima suele ser muy baja en las víctimas. Por lo tanto, sus niveles de tolerancia a la frustración son muy bajos" (Psicólogo, entrevista personal, 28 de noviembre de 2018).

Los encuestados indicaron que las tendencias suicidas pueden surgir de la falta de capacidad para manejar o enfrentar obstáculos junto con la retirada de la sociedad. Los psicólogos entrevistados en el estudio también sugirieron que los problemas subyacentes de salud mental son una condición necesaria para las tendencias suicidas, como se describe a continuación: "Las causas que mencioné anteriormente pueden desencadenar el suicidio, pero la raíz del problema es la baja autoestima. Una persona que se suicida seguramente decidió suicidarse porque tenía una autoestima desequilibrada” (Psicólogo, entrevista personal, 26 de noviembre de 2018).

Los entrevistados vincularon los problemas de salud mental que conducen a intentos de suicidio con aislamiento y un deterioro de las redes de apoyo. Así, declararon que “... comienzan a quedarse sin opciones, como esos grupos de amigos, grupos familiares o grupos de apoyo" (Psicólogo, entrevista personal, 20 de noviembre de 2018). 


\section{Alcohol y drogas (8 entrevistas)}

El abuso de sustancias como el alcohol o las drogas ilícitas se mencionó regularmente en las entrevistas como una posible causa o factor que influye en la tasa de suicidios en Nebaj. Aproximadamente el 42 \% de los encuestados mencionaron que el alcohol o las drogas estaban involucradas o desempeñaban un papel en llevar a las personas a un comportamiento suicida. Como describió un psicólogo, aunque hay pocos datos cuantitativos para respaldar la afirmación, las drogas y el alcohol se consideran comunes en Nebaj: "El consumo de alcohol y drogas en Nebaj es bastante grave. No tengo estadísticas, pero creo que esto es algo que dificulta las cosas”. Además, “... hay muchas formas o situaciones diferentes que las personas atraviesan para llegar a pensamientos suicidas. Uno de estos problemas es el abuso del alcohol” (Psicólogo, entrevista personal, 28 de noviembre de 2018).

La disponibilidad y el consumo del alcohol también se enumeraron como una causa para otros factores que pueden influir en el suicidio, lo que sugiere un efecto indirecto sobre los suicidios en Nebaj. Según lo descrito por un juez, el abuso del alcohol puede correlacionarse con familias que se separan y eventualmente desempeñar un papel en influir en el comportamiento suicida: "Veo la desintegración familiar y el abuso del alcohol como las causas más comunes" (Jueza, entrevista personal, 27 de noviembre de 2018).

Los psicólogos y los funcionarios del Gobierno también señalaron el papel que puede jugar el alcohol en el intento de suicidio. Según lo mencionado por un psicólogo, es bastante común que aquellos que intentan suicidarse estén bajo la influencia del alcohol cuando son ingresados en el hospital.: “... más del $50 \%$ de los hombres que fueron admitidos debido a un intento de suicidio estaban bajo los efectos [del alcohol] cuando intentaron acabar con sus vidas" (Psicólogo, entrevista personal, 20 y el 27 de noviembre de 2018).

El uso de drogas fue percibido como un problema frecuente, aunque tal vez no esté directamente relacionado con el suicidio. Un encuestado señaló al uso de drogas como un signo de conducta imprudente en los jóvenes que podría conducir a conductas suicidas:

Hay niños de doce años que ya usan algún tipo de sustancia, tal vez inhalando pegamento o diluyente, consumiendo alcohol o fumando marihuana. Comienzan a edades muy tempranas, experimentando con estas cosas porque definitivamente no pueden controlarse a sí mismos (Psicólogo, entrevista personal, 20 de noviembre de 2018).

\section{¿Cuáles son los factores a nivel familiar que motivan el suicidio?}

Además de los problemas individuales, los entrevistados mencionaron que los problemas familiares son una característica destacada de los intentos de suicidio o de los suicidios consumados. Los encuestados identificaron la separación o desintegración y la violencia familiar como problemas que juegan un papel en la crisis del suicidio.

\section{Separación familiar (9 entrevistas)}

Casi la mitad de los encuestados en este estudio destacaron la importancia de la disolución de las familias ante el fenómeno del suicidio en Nebaj. La desintegración de las familias está relacionada con problemas matrimoniales, violencia doméstica e incluso migración, ya que los padres pueden decidir migrar a los Estados Unidos y dejar que sus hijos sean atendidos por sus 
parejas u otros miembros de la familia. Al describir cómo la familia puede influir en el comportamiento suicida, las entrevistas identificaron la desintegración familiar, abandono por padres como causas a nivel familiar. A raíz de una separación, el cambio resultante en las relaciones y disponibilidad de los padres puede afectar a los jóvenes en Nebaj. Se señaló la falta de atención de los padres debido a la disolución de la familia. Los encuestados dijeron que las víctimas, sufren violencia psicológica y no tienen la atención de sus padres. Según lo descrito por el psicólogo:

Lo que más observé en los jóvenes fueron los problemas familiares, como la desintegración familiar. Y se ven afectados por la separación de sus padres y todo. Además, por el hecho de que su padre o madre no les presten atención (Psicólogo, entrevista personal, 20 de noviembre de 2018).

La separación familiar también está vinculada a la migración, ya que se dice que los padres dejan a su familia para viajar a los Estados Unidos, impactando a la familia que se queda atrás. En relación con otro factor previamente mencionado en los suicidios, los encuestados sugirieron que el estancamiento económico es un motor para la emigración: “... no hay oportunidades de trabajo aquí en Nebaj”. El proceso de migración también conlleva un riesgo financiero sustancial, ya que las familias deben pagar el transporte a los Estados Unidos, generalmente tomando un préstamo informal o utilizando su casa como garantía, Según lo descrito por un trabajador social: "La separación familiar también, porque abandonan a sus hijos, esposa y se van. Si no pueden cruzar la frontera, regresan con un problema familiar” (Trabajador social, entrevista personal, 28 de noviembre de 2018).

Por lo tanto, la desintegración de las familias, ya sea a través del divorcio o por la migración, es una razón comúnmente citada que afecta a los jóvenes en Nebaj. Los encuestados señalaron que la falta de apoyo familiar, la ausencia de padres o las relaciones cambiantes asociadas con la disolución familiar son factores consistentes en el suicidio en el municipio.

\section{Problemas familiares (15 entrevistas)}

Al igual que los problemas de desintegración familiar, los encuestados designaron con frecuencia los problemas familiares, como la falta de comunicación y atención y la violencia doméstica, como posibles factores que motivan el suicidio juvenil. Estos temas a menudo se discuten como resultado de una separación familiar y, por lo tanto, no pueden separarse por completo del tema de la desintegración familiar. En total, 15 de los 19 entrevistados hicieron énfasis en que los problemas dentro de la familia podrían estar relacionados con el aumento de los suicidios en Nebaj.

\section{¿Cuáles son los factores a nivel comunitario que motivan el suicidio?}

$\mathrm{Al}$ describir la comunidad de Nebaj y los factores que pueden estar asociados con el suicidio, los entrevistados indicaron la emigración debido al estancamiento económico en el municipio como un componente potencial de los suicidios de los jóvenes.

\section{Migración (6 entrevistas)}

En estas entrevistas los participantes vincularon la emigración de Nebaj con el suicidio. En este caso, los encuestados generalmente advirtieron la falta de oportunidades económicas como un estímulo para la emigración de Nebaj, y el efecto resultante en la familia como la 
creación de un entorno propicio para el comportamiento suicida. Específicamente, los encuestados relacionaron la "migración constante a los Estados Unidos" a condiciones asociadas con el suicidio. Mencionaron, asimismo, cómo los padres que se van a los Estados Unidos a trabajar y hacen que sus hijos permanezcan en Nebaj pueden crear un vacío en la estructura para los niños. Las entrevistas describen, "incluso casos de madre y padre que emigran y dejan a sus hijos con sus abuelos”.

En los casos donde los padres "se van al extranjero y dejan a sus hijos", las madres solteras pueden tener dificultades para mantener su hogar y proporcionar una estructura parental. Según lo descrito por un trabajador social:

Tienen padres que se van a los Estados Unidos, hay desintegración familiar y los niños se sienten solos. Es posible que la madre no pueda aconsejar o guiar a sus hijos y sientan que ya no tienen escapatoria (Trabajadora social, entrevista personal, 27 de noviembre de 2018).

$\mathrm{Al}$ referirse a la migración de género, específicamente un aumento en las mujeres migrantes, un psicólogo identificó las consecuencias para los niños en Nebaj: "Las mujeres buscan alternativas migrando. Huyen a los Estados Unidos. Una vez que se establecen, comienzan a enviar dinero, envían de todo. Pero los niños siguen siendo vulnerables” (Psicólogo, entrevista personal, 28 de noviembre de 2018).

A partir de la descripción de los encuestados, es evidente que algunos participantes asocian el fenómeno de la emigración de Nebaj a los Estados Unidos con la fractura de las familias y ven el entorno resultante como uno que permite la ideación suicida.

\section{¿Cómo innteractúan estos factores?}

Como se estableció anteriormente, la interacción más clara entre la comunidad, la familia y los factores individuales en el suicidio se debe a la falta de oportunidades económicas en Nebaj y la consiguiente emigración de los padres de la zona a los Estados Unidos. Luego, los encuestados afirmaron que la migración tiene el efecto de inducir la separación y la desintegración de la familia, y este cambio en la estructura familiar puede conducir a un comportamiento suicida por parte de los hijos de migrantes que han permanecido en Nebaj. Sin embargo, es importante tener en cuenta que esta afirmación no se puede probar con los datos de la entrevista y requeriría encuestar a los hogares en Nebaj, así como entrevistar a las personas que han intentado suicidarse para confirmar o rechazar esta hipótesis.

\section{¿Qué se necesita para prevenir los intentos de suicidio?}

A los participantes en este estudio se les preguntó qué puede hacer la municipalidad para abordar el asunto del suicidio y cuáles son los desafíos existentes para tratar los suicidios. Un tema común en las respuestas fue la falta de recursos, personal y especialistas dedicados para responder a las necesidades de una población grande.

\section{Recomendaciones generales para prevenir los intentos de suicidio}

Las partes interesadas reconocieron sistemáticamente la falta de personal como un impacto en la capacidad de la comunidad para abordar el suicidio. La identificación de estos

problemas conduce naturalmente a las recomendaciones de los participantes. Los encuestados en estas entrevistas mencionaron cuatro cosas que deben hacerse para abordar el asunto del 
suicidio en Nebaj: (1) más énfasis en la divulgación y concientización local, (2) inversión en especialistas y organizaciones dedicadas, (3) una meta de tener acciones dirigidas que se deriven de un plan de acción, y (4) la necesidad de colaboración interinstitucional dirigida por la municipalidad.

Alcance local y sensibilización: Al considerar la escala del problema, el área geográfica de Nebaj y la población que necesita ser atendida, los encuestados sugirieron que los esfuerzos deben ser difundidos en todo el municipio y no localizados en la capital departamental. Según un oficial de policía, se deben hacer esfuerzos para "abordar estos temas a nivel comunitario y no tanto en la... ciudad capital". Este tema fue repetido por otros, lo que sugiere que se deben hacer esfuerzos para garantizar que todas las áreas de Nebaj sean alcanzadas por igual. En este sentido, los encuestados sugirieron que la falta de conocimiento de los recursos disponibles para las personas es un problema, así como la falta de comprensión sobre los problemas de salud mental por parte del público.

Especialistas dedicados: Los encuestados mencionaron en repetidas ocasiones la falta de recursos y personas que traten el asunto del suicidio en Nebaj. En relación con las campañas de sensibilización sobre la disponibilidad de servicios, los encuestados identificaron que la falta de recursos dedicados estaba obstaculizando los esfuerzos para responder al problema. Al notar la falta de psicólogos disponibles, un encuestado sugirió que el gobierno municipal debería "designar a un psicólogo para que brinde más servicios a las familias".

Los encuestados también señalaron la necesidad de profesionales que trabajen fuera del hospital que puedan ayudar a las personas a identificar y alcanzar los servicios que necesitan, para que puedan "brindarles todas las herramientas necesarias para que puedan ayudar a las víctimas”. Según lo descrito por un psicólogo:

... Necesitan buscar ayuda profesional. Los profesionales deben ser los que brinden orientación sobre qué hacer con la víctima. Porque muchas personas no quieren ir al hospital o no quieren contactar a un profesional para que les brinde ayuda (Psicólogo, entrevista personal, 6 de diciembre de 2018).

Algunos entrevistados también pidieron la creación de programas de capacitación para padres y familias que ayuden con la detección temprana y capaciten a los niños a manejar situaciones difíciles y superar obstáculos. Al describir los esfuerzos que debe realizar la municipalidad, un psicólogo dijo que deberían “... crear más programas, trabajar con jóvenes, capacitar a los padres y trabajar con los niños. Esos factores serían muy importantes”. Discutir puntos específicos de acción lleva a la siguiente recomendación por parte de los encuestados.

Más acción: Varios de los encuestados mencionaron la necesidad de pasar de tener reuniones generales a desarrollar planes específicos de acción con cronogramas. Según lo descrito por un entrevistado, con demasiada frecuencia se llevan a cabo reuniones, pero luego “... los documentos terminan en un archivo”. Un trabajador social declaró lo siguiente respecto de la cuestión de los retrasos y las reuniones que no resultan en acciones: "Durante este año, si no me equivoco, hemos estado discutiendo el suicidio, ¿̇verdad? Pero hay más reuniones en lugar de acciones" (Trabajador social, entrevista personal). 
Esto sugiere que, si bien puede haber un apoyo interinstitucional, si no se definen las responsabilidades y no se implementan los plazos, habría poca colaboración. La necesidad de tener un plan de acción claramente definido, con medidas de responsabilidad que no dupliquen los esfuerzos dentro de Nebaj depende de la siguiente recomendación:

Colaboración con instituciones en Nebaj: Los encuestados identificaron en repetidas ocasiones que, para abordar el tema del suicidio, todas las instituciones relevantes en Nebaj tenían que trabajar juntas. Según lo declarado por un representante indígena, "el trabajo para la prevención del suicidio debe hacerse de manera transversal”. Los miembros de la comunidad que no trabajan en el sector de la salud también destacaron que "se podrían lograr muchas cosas si trabajáramos en equipo”.

\section{Resulitados de la revisión de casos}

Como parte de este estudio, los investigadores se contactaron con instituciones locales en Nebaj para solicitar datos no identificados relacionados con intentos de suicidio y suicidios consumados. Como se discutió en los hallazgos cualitativos, las instituciones que abordan el suicidio a menudo están aisladas, no trabajan juntas y no recopilan información con los mismos fines. Como tal, los datos disponibles están fragmentados y las estadísticas recibidas de diferentes fuentes son difíciles de alinear entre conjuntos. Sin embargo, a pesar de estas limitaciones, los datos recopilados de la revisión oficial de casos proporcionan una imagen útil, aunque incompleta, de la prevalencia estadística sobre intentos de suicidios y suicidios consumados en Nebaj. Además, las limitaciones estructurales de los datos revelaron la necesidad de mejorar las herramientas de recopilación si el objetivo de las instituciones y de la municipalidad es recopilar datos más precisos sobre el fenómeno del suicidio en la región.

Para analizar supuestos intentos de suicidio y suicidios consumados, esta investigación utilizó datos que van desde 2016 hasta 2018, tanto de la PNC como del hospital público de Nebaj. En comunicación con la PNC, indicaron que solo registran casos de suicidios consumado por asfixia debido a un ahorcamiento. Esto se debe al hecho de que los suicidios no se consideran un delito en Guatemala y, por lo tanto, no están en el ámbito de una investigación policial. Además, es probable que la PNC clasifique como suicidios solamente los casos obvios (por ejemplo, muerte por ahorcamiento). ${ }^{2}$

Como parte del proceso de revisión de casos, los investigadores examinaron los registros desidentificados individuales y encontraron 27 casos de suicidios consumados que se documentaron entre el 2016 y el 2018. Como se muestra en la Tabla 1, las víctimas de suicidio eran predominantemente hombres, de 20 años o menos. Aunque el $40 \%$ de las víctimas tenían más de 20 años, la edad promedio era relativamente baja: 28,3 años. Quince víctimas eran solteras, siete víctimas estaban casadas y cuatro víctimas no estaban casadas, sino que vivían con sus parejas. ${ }^{3}$

\footnotetext{
${ }^{2}$ Los oficiales de la PNC proporcionaron estadísticas agregadas de suicidios consumados a partir de 2017, ya que la información no estaba disponible para las muertes designadas como suicidios antes de ese año. Según informes oficiales, en 2017, solo se registraron 10 casos (todos hombres) en comparación con los 13 registrados en 2018 (12 hombres y 1 mujer).

${ }^{3}$ Faltaba información sobre el estado civil de una víctima.
} 
Tabla 1. Rango de edad de las víctimas de suicidio documentado por la PNC para el 2017-2018

\begin{tabular}{|c|c|c|}
\hline \multirow{2}{*}{ Rango de edad } & \multicolumn{2}{|c|}{ Víctimas } \\
\cline { 2 - 3 } & \multicolumn{2}{|c|}{ Número } \\
\hline $10-20$ & 16 & 59,3 \\
\hline $21-30$ & 4 & 14,8 \\
\hline $31-40$ & 2 & 7,4 \\
\hline Más de 41 & 5 & 18,5 \\
\hline Total & 27 & 100,0 \\
\hline Género & \multicolumn{2}{|c|}{} \\
\hline Masculino & 24 & 88,9 \\
\hline Femenino & 3 & 11,1 \\
\hline Total & 27 & 100,0 \\
\hline
\end{tabular}

Fuente: Revisión del expediente de la PNC realizada por investigadores en el país.

Todos los suicidios fueron por asfixia por ahorcamiento, fuera de la residencia de la víctima (12 casos) o dentro ( 15 casos). El consumo de alcohol se indicó como un factor subyacente en 17 casos y en 3 la depresión se indicó como una razón potencial. Los posibles factores potenciales no se documentaron en 7 de los casos.

El hospital en Nebaj proporcionó datos agregados de 129 casos de intentos de suicidio y consumados desde 2016 hasta 2018, que se muestran en la Tabla 2. Sin embargo, los formularios de recopilación de datos del hospital se modificaron año tras año y, como tal, no todos están disponibles (por ejemplo, género, ubicación). Además, los resultados de los casos no se codificaron de manera consistente y carecían de claridad. Asimismo, no existe suficiente información para poder vincular cualquier caso con los registros de la PNC.

La Tabla 2 también muestra el recuento y el porcentaje de intentos y suicidios consumados por sexo, rango de edad y método. Estos datos sugieren que tanto los suicidios consumados como los intentos de suicidio son más comunes en los hombres. El rango de edad más frecuente para los suicidios consumados fue de 11 a 20 años (50 \%), mientras que los intentos de suicidio fueron predominantemente en el rango de edad de 21 a 30 años (43,5\%). En particular, la ingestión de químicos fue el método más común para los intentos y los suicidios consumados según lo reportado por el hospital, ya que casi 3 de cada 4 casos involucraron la ingestión de veneno (71,4 \% de los suicidios consumados y 75,6 \% de los intentos de suicidio). Específicamente, el químico más comúnmente utilizado fue el Gramoxone, un herbicida utilizado para controlar las malezas en la agricultura. La mayoría de los casos documentados en las hojas de trabajo del hospital fueron casos del municipio de Nebaj (7 suicidios consumados y 58 intentos), pero también se documentaron casos en los siguientes municipios vecinos: Chajul (2 suicidios y 8 intentos), Cotzal (1 suicidio y 5 intentos) y Cunen (10 intentos). Esto sugiere que el suicidio era más frecuente en Nebaj, sin embargo, podría ser el caso de que los intentos de suicidio que ocurrieron dentro de Nebaj fueran probablemente referidos al hospital de Nebaj. Alternativamente, esto podría indicar que los suicidios consumados que ocurren dentro de los otros municipios no serían enviados al hospital de Nebaj. 
En conjunto, la revisión de casos presenta una imagen compleja pero consistente de suicidios en el área. A través de los años y las fuentes de datos se evidenció que es más probable que los jóvenes intenten suicidarse y que la mayoría de los incidentes involucren a una víctima de 30 años o menos. Además, los datos de la PNC parecen abarcar solo a las víctimas que se han suicidado por ahorcamiento, lo que probablemente sea una particularidad del proceso de recopilación de datos. El hospital de Nebaj se ocupa de una mayor variedad de formas de suicidio, pero por lo general hace frente a intoxicaciones químicas por ingesta de un herbicida común.

Tabla 1. Distribución de género, edad y forma de suicidio para suicidios consumados o intentos para los años 2016-2018, se muestran en porcentajes

\begin{tabular}{|c|c|c|c|c|c|c|}
\hline & \multicolumn{2}{|c|}{2016} & \multicolumn{2}{|c|}{2017} & \multicolumn{2}{|c|}{2018} \\
\hline & $\begin{array}{c}\text { Suicidios } \\
\text { consumados }\end{array}$ & $\begin{array}{c}\text { Intentos } \\
\text { de } \\
\text { suicidio }\end{array}$ & $\begin{array}{c}\text { Suicidios } \\
\text { consumad } \\
\text { os }\end{array}$ & $\begin{array}{c}\text { Intentos } \\
\text { de } \\
\text { suicidio }\end{array}$ & $\begin{array}{c}\text { Suicidios } \\
\text { consumad } \\
\text { os }\end{array}$ & $\begin{array}{c}\text { Intentos } \\
\text { de } \\
\text { suicidio }\end{array}$ \\
\hline \multicolumn{7}{|l|}{ Género } \\
\hline Masculino & 60 & 50 & 50 & 46,8 & 60 & 46,9 \\
\hline Femenino & 20 & 25 & $\mathrm{O}$ & 23,4 & 20 & 28,1 \\
\hline Desconocido & 20 & 25 & 50 & 29,8 & 20 & 25 \\
\hline \multicolumn{7}{|l|}{ Rango de edad } \\
\hline menos de 10 & $\mathrm{O}$ & 8,3 & 0 & $\mathrm{O}$ & $\mathrm{O}$ & $\mathrm{O}$ \\
\hline $11-20$ & 60 & 50 & 75 & 40,4 & 20 & 31,2 \\
\hline $21-30$ & 20 & 25 & 25 & 51,1 & 20 & 53,1 \\
\hline $31-40$ & 20 & 8,3 & $\mathrm{O}$ & 6,4 & 20 & 3,1 \\
\hline Más de 41 & $\mathrm{O}$ & 8,3 & 0 & 2,1 & 20 & 12,5 \\
\hline \multicolumn{7}{|l|}{ Forma de suicidio } \\
\hline Ingesta química & 80 & 75 & 50 & 72,3 & 80 & 81,2 \\
\hline Ingesta de plantas & $\mathrm{O}$ & 8,3 & $\mathrm{O}$ & $\mathrm{O}$ & $\mathrm{O}$ & $\mathrm{O}$ \\
\hline $\begin{array}{c}\text { Ingesta de } \\
\text { medicamentos }\end{array}$ & $\mathrm{O}$ & $\mathrm{O}$ & 0 & 2,1 & $\mathrm{O}$ & $\mathrm{O}$ \\
\hline Ahorcamiento & $\mathrm{O}$ & 8,3 & 50 & 8,5 & 20 & 9,4 \\
\hline Alcoholismo agudo & O & 5,6 & $\mathrm{O}$ & 4,3 & $\mathrm{O}$ & 6,2 \\
\hline $\begin{array}{l}\text { ¿Cortar venas } \\
\text { muñecas? }\end{array}$ & $\mathrm{O}$ & $\mathrm{O}$ & 0 & 2,1 & $\mathrm{O}$ & $\mathrm{O}$ \\
\hline Desconocido & 20 & 2,8 & $\mathrm{O}$ & 10,6 & $\mathrm{O}$ & 3,1 \\
\hline $\begin{array}{c}\text { Recuento total de } \\
\text { suicidios }\end{array}$ & 5 & 36 & 4 & 47 & 5 & 32 \\
\hline
\end{tabular}

Fuente: Departamento de Estadística del Hospital Nebaj.

\section{Implicaciones, conclusiones y recomendaciones}

Según la psicóloga Bader Burihan Sawaia (2009), detrás de la desigualdad social está el sufrimiento, el miedo, la humillación, pero también el extraordinario milagro humano de la voluntad de ser feliz y empezar de nuevo incluso cuando la situación puede parecer 
desesperada. Sin duda, los mayas ixiles de Nebaj han sufrido tremendamente como pueblo y sus desafíos colectivos de salud mental están profundamente arraigados en un contexto social e histórico complejo de violencia, miedo, explotación y marginación. Este estudio de caso cualitativo sirve para corroborar lo que muchos periodistas y otras personas familiarizadas con Nebaj han informado anteriormente. En general, hay una superposición de factores complejos que contribuyen al comportamiento suicida de riesgo como se observa en la literatura sobre el tema, la prensa guatemalteca y los resultados de nuestro trabajo. Si bien este estudio proporciona información valiosa sobre la situación local, debido al hecho de que existen pocos esfuerzos de colaboración entre las instituciones locales para documentar los suicidios consumados y los intentos, no se obtuvo evidencia de una prevalencia de suicidios superior a la media en la región. Esto no significa que el suicidio en la región Ixil no sea notable o deba ser relegado de alguna manera a una prioridad menor. De hecho, es muy probable que en Nebaj haya suicidios no reportados, que son muertes que se registran incorrectamente. Los estudios futuros del suicidio en Nebaj deberían considerar el impacto de los suicidios no reportados entre las muertes clasificadas como no determinadas y accidentes. Al establecer metas para la reducción del suicidio, las estrategias de prevención deben evaluar el impacto de los suicidios no reportados derivados de datos oficiales (OPS, 2014; Pritchard \& Hean, 2008).

Nuestra consideración de los problemas de salud mental pública entre las poblaciones indígenas de Guatemala es muy limitada. Las preocupaciones por la desconfianza cultural, el estigma y las diferencias en los comportamientos de búsqueda de ayuda entre los mayas ixiles deben tenerse especialmente en cuenta al diseñar las intervenciones. Además, las manifestaciones e interpretaciones de angustia dentro de estas poblaciones indígenas son probablemente distintas a las de la población guatemalteca en general. Las actitudes culturales hacia el suicidio pueden ser una barrera para las estrategias efectivas de prevención (Pritchard \& Hean, 2008). El antropólogo Edward T. Hall desarrolló un concepto conocido como el modelo iceberg para comprender la cultura en la década de 1970 (Hall, 1976; Hall, 1990). Según Hall, la complejidad de la cultura humana es extremadamente difícil de entender y, dado que los aspectos visibles de la cultura (es decir, comida, idioma, música, artesanía, vestimenta) solo representan un pequeño porcentaje de la complejidad que constituye el todo. La cultura profunda también incluye actitudes hacia el suicidio, incluidas las condiciones en las que las respuestas al estrés pueden generar intentos de suicidio. 
Figura 3. Concepto de Iceberg Cultural

\section{EL ICEBERG CULTURAL}

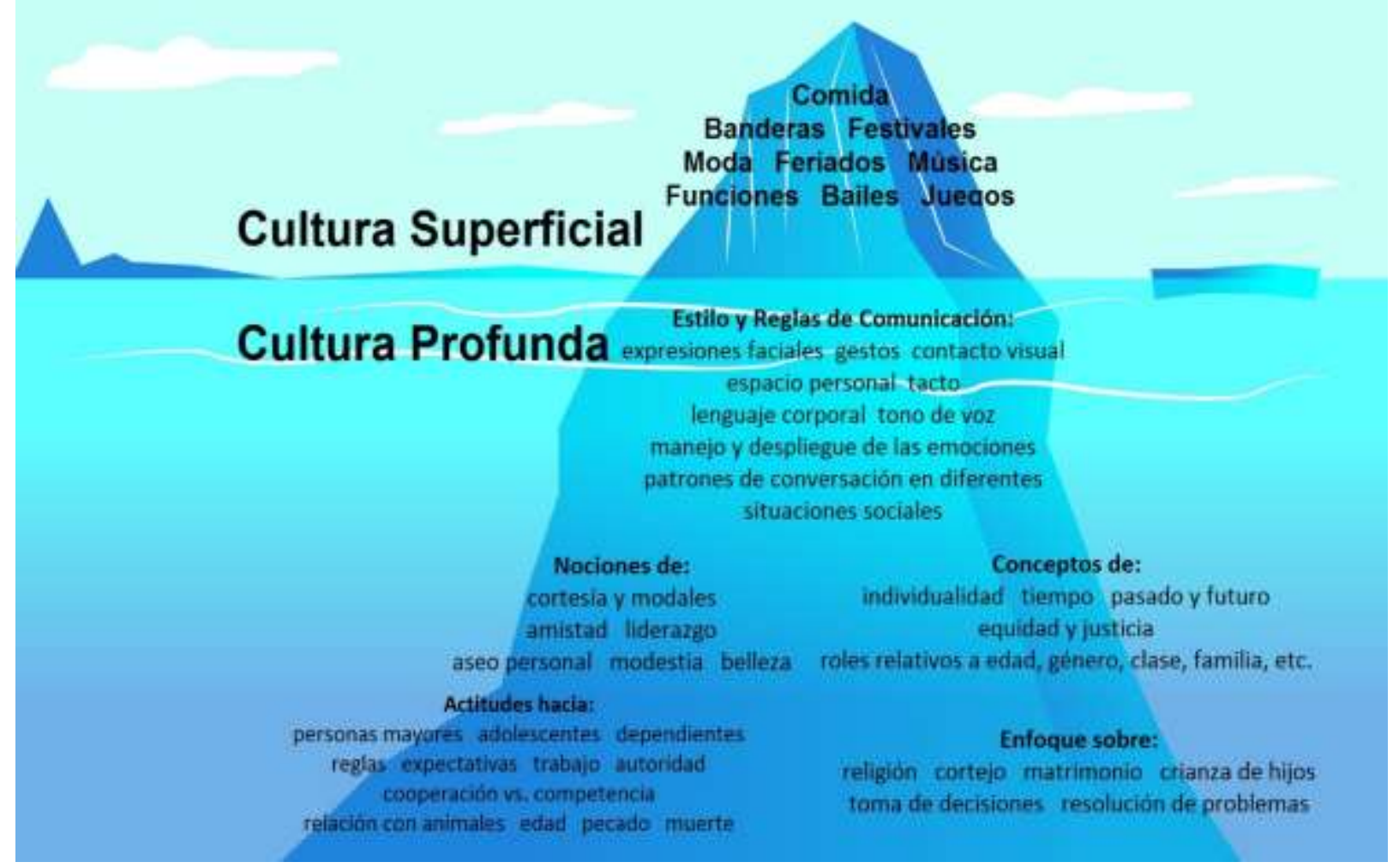

Fuente: Long (2013).

Un tema común entre los encuestados es que las intervenciones de prevención y tratamiento culturalmente sensibles para los comportamientos suicidas son extremadamente limitadas, especialmente en Guatemala. En este sentido, un área poco estudiada es el grado en que las intervenciones enfocadas en reducir los factores de riesgo (por ejemplo, la desesperanza en la comunidad) y mejorar los factores o apoyos de protección culturalmente relevantes (por ejemplo, los lazos con los ancianos o las tradiciones culturales) pueden disminuir las tendencias suicidas. Los programas de detección para identificar factores de riesgo conocidos para el suicidio han demostrado ser particularmente efectivos. Se necesita más investigación en la región Ixil para desarrollar herramientas de detección estandardizadas culturalmente para este propósito. En relación con esta falta de programas, existen desafíos importantes para medir el impacto de cualquier programa que pueda implementarse, ya que esencialmente no hay grupos de comparación para medir el éxito. El tema de los suicidios estaba relacionado con la falta de recursos gubernamentales, especialistas calificados y dedicados para responder a las necesidades de una población de gran tamaño. La investigación ha demostrado que los programas educativos diseñados para abordar el conocimiento profesional, las actitudes y la competencia de los profesionales de la salud pública en el tratamiento de conductas suicidas tienen beneficios directos (Chan, Chien \& Tso, 2008). Se recomienda un programa mínimo de capacitación de dos días para los profesionales. Esto debe incluir médicos, patólogos, 
profesionales de la salud mental, clínicos de salud pública, policías e investigadores criminales, y ciertas organizaciones de la sociedad civil que trabajan en el área.

Hay investigaciones sólidas que muestran que las iniciativas para restringir el acceso a métodos letales reducen los suicidios por esos métodos. La ingestión de pesticidas en Nebaj es un medio común para intentar suicidarse, por lo cual se deben tomar medidas específicas para restringir el acceso a estos. Las estrategias de prevención del suicidio en Nebaj deben tratar de contrarrestar las percepciones de que ahorcarse o ingerir pesticidas es un método limpio, indoloro y rápido que se hace fácilmente. Sin embargo, las autoridades deberían considerar estrategias de intervención específicamente diseñadas para contrarrestar estas percepciones generalizadas. Las estrategias de prevención deben, además, tratar de compartir las dolorosas realidades de estos comportamientos suicidas.

Recientemente, un grupo sustancial de evidencia basada en Ensayos Controlados Aleatorios (ECA) ha demostrado una reducción en los intentos de suicidio y la ideación después de los programas de salud mental y sensibilización sobre el suicidio en las escuelas (Zalsman et al., 2016). Además, los programas grupales, de cognitiva conductual y los basados en la familia diseñados para prevenir el suicidio son prometedores (Calear et al., 2016; Asamow et al., 2017). Según nuestra investigación, los programas de prevención e intervención suicida en Nebaj deben tener en cuenta la emigración y la reintegración de los migrantes. Las presiones derivadas de la falta de oportunidades económicas, las prácticas de préstamos abusivos y la consiguiente deuda y pérdida de tierras, así como las estructuras familiares debilitadas son preocupaciones persistentes. Los encargados de formular políticas deben tener en cuenta los efectos de la separación de los padres en los comportamientos suicidas, incluyendo los padres que han emigrado. Se deben tomar pasos específicos para compensar los impactos en la juventud.

Es necesario realizar más actividades de investigación, utilizando especialmente métodos cualitativos, para comprender mejor los comportamientos suicidas en Nebaj y sus alrededores (Gibson, Benson \& Brand, 2012). Las anécdotas, los relatos de segunda mano y las fuentes de los periódicos no deben guiar las conclusiones de la investigación. Las entrevistas estructuradas y los enfoques de métodos mixtos deben explorarse con individuos que participan en conductas suicidas. Esto es necesario para generar ideas para promover intervenciones exitosas para las personas que viven en un estado de comportamiento suicida. De acuerdo con Biddle et al. (2013), la vigilancia y protección excesiva de los sujetos de investigación podrían estar evitando que algunas personas obtengan importantes beneficios de participación. Además, después de un intento de suicidio, las agencias de salud pública en Nebaj deben abordar las brechas en colaboración y coordinación para garantizar que las intervenciones de seguimiento y el cumplimiento del tratamiento se realicen en un esfuerzo más concertado para disminuir los nuevos intentos.

Aunque la evidencia está lejos de ser concluyente, los encuestados sugirieron que hay comportamientos suicidas por imitación. Las estrategias para influir en cómo los medios informan sobre el suicidio deben implementarse y evaluarse en Nebaj. Además, se necesita más investigación para evaluar las plataformas de redes sociales como Facebook y WhatsApp por su 
potencial para la prevención del suicidio de jóvenes en Nebaj. El psicólogo social y sacerdote salvadoreño Ignacio Martín-Baró argumentó que la investigación es una herramienta poderosa para exponer los sistemas sociales opresivos y el engaño generalizado en un esfuerzo por poner fin a las prácticas injustas, lo que afecta el cambio social (Goodman, Walling, \& Ghali, 2010). Esta es también nuestra esperanza.

\section{Referencias}

Ammerman, B. A., Kleiman, E. M., Uyeji, L. L., Knorr, A. C. \& McCloskey, M. S. (2015). Comportamiento suicida y violento: El papel de la ira, la desregulación de las emociones y la impulsividad. Personality and Individual Differences,79, 57-62. https://doi.org/10.1016/j.paid.2015.01.044

Anderson, J., Hurst, M., Marques, A., Millara, D., Moya, S., Pover, L. \& Stewart, S. (2012) Comprensión del comportamiento suicida en jóvenes referidos al especialista CAMHS: A proyecto de investigación clínica cualitativa. Journal of Child Psychotherapy, 38(2), 130-153. https://doi.org/10.1080/0075417X.2012.684484

Asamow, RJ., Hughes, J. L., Babeva, K. N. \& Sugar, C. A. (2017). Tratamiento familiar cognitivo-conductual para la prevención del intento de suicidio: un ensayo de control aleatorio. Journal of the American Academy of Child \& Adolescent Psychiatry, 56(6), 506-514. https://doi.org/10.1016/j.jaac.2017.03.015

Azuero, A. J., Arreaza-Kaufman, S., Coriat, J., Tassinari, S., Faria, A., CastañedaCardona \& Rosselli, D. (2017). El suicidio en la población indígena de América Latina: una revisión sistemática. Revista Colombiana de Psiquiatría, 46(4). https://doi.org/10.1016/j.rcpeng.2017.09.001

Barreno Castillo, R. (2018, septiembre 23). El gran desafío de Nebaj. Prensa Libre. https://www.pressreader.com/guatemala/prensa-libre/20180923/282312500989989.

Bell, G. (2017). "This Isn't Underground; This is the Highlands": Mayan-Language Hip Hop, Cultural Resilience, and Youth Education in Guatemala. Journal of Folklore Research, 54(3), 167-197. https://doi.org/10.2979/jfolkrese.54.3.02

Biddle, L., Cooper, J., Owen-Smith, A., Klineberg, E., Bennewith, O., Hawton, K., Kapur, N. Donovan, J. \& Gunnell, D. (2013). Entrevistas cualitativas con poblaciones vulnerables: Experiencias de individuos participantes en investigaciones basadas en el suicidio y autolesiones. Journal of Affective Disorders, 145, 356-362. https://doi.org/10.1016/j.jad.2012.08.024

Biddle, L., Donavan, J., Owen-Smith, A., Potokar, J., Longson, D., Hawton, K., Kapur, N. \& Gunnell, D. (2010). Factores que influyen en la decisión de utilizar el ahorcamiento como método de suicidio: estudio cualitativo. The British Journal of Psychiatry, 197, 320-325. https://doi.org/10.1192/bjp.bp.109.076349 
Bucheli, M. (2008). Multinational Corporations, Totalitarian Regimes and Economic Nationalism: United Fruit Company in Central America, 1899-1975. Business History, 5O(4), 433-454. https://doi.org/10.1080/00076790802106315

Calear, A. L., Christensen, H., Freeman, A., Fenton, K., et al. (2016). Una revisión sistemática de las intervenciones de prevención del suicidio psicosocial para jóvenes. European Child \& Adolescent Psychiatry, 25(5), 467-482. https://doi.org/10.1007/s00787-015-0783-4

Carmack, R. M. (1988). Harvest of violence: The Maya Indians and the Guatemalan crisis. University of Oklahoma Press.

Censo. (2019, septiembre 26). Censo de Población y Vivienda. XII Censo Nacional de Población y VII de Vivienda en Guatemala, Instituto Nacional de Estadística de Guatemala. https://www.censopoblacion.gt/

Chan, S. W., Chien, W. \& Tso, S. (2008) La evaluación cualitativa de un programa de prevención y manejo del suicidio por parte de enfermeras generales. Journal of Clinical Nursing, 17, 2884-2894.

Chang, S., Sterne, J. A., Lu, T. \& Gunnell, D. (2010). Suicidios “ocultos” entre muertes certificadas como intención indeterminada, accidente por envenenamiento por pesticidas y accidente por asfixia en Taiwán. Social Psychiatry and Psychiatric Epidemiology, 45, 143-152. https://doi.org/10.1007/s00127-009-0049-x

Chu, C., Walker, K. L., Stanley, I. H., Hirsch, J. K., Greenberg, J. H., Rudd, M. D. \& Joiner, T. E. (2018). Déficit de resolución de problemas percibidos e ideación suicida: evidencia de los roles explicativos de pertenencia frustrada y la carga percibida en cinco muestras. Journal of Personality and Social Psychology, 115(1), 137-16o. https://doiorg.proxyoo6.nclive.org/10.1037/psppooo0152

Cordero, H. (2018, julio 20). Enrique Pérez Ceto. Prensa Libre. https://www.pressreader.com/guatemala/prensa-libre/20180720/281917363863320

Cordero, H. (2019, mayo 20). ¿Por qué siguen ocurriendo suicidios de menores en Quiché?. Prensa Libre. https://www.prensalibre.com/ciudades/quiche/por-que-siguenocurriendo-suicidios-de-menores-en-quiche/

Fanon, F. (1967). Black Skin, White Masks. Grove.

Fanon, F. (1968). Wretched of the Earth. Grove.

Gibson, S., Benson, O. \& Brand, S. L. (2012). Hablando de suicidio: confidencialidad y anonimato en la investigación cualitativa. Nursing Ethics. https://10.1177/0969733012452684 
Gilgun, J. F. (2009). Una revisión de, The Sage Handbook of Grounded Theory. Journal of Family Theory \& Review, 1(2), 106-109. https://doi-org.proxyoo6.nclive.org/10.1111/j.1756-2589.2009.00013.x

Glaser, B. G. (1992). Fundamentos del análisis de teoría fundamentada. Sociological Press.

Goldblum, P., Espelage, D. L., Chu, J. \& Bongar, B. (2015). Suicidio y acoso juvenil: desafíos y estrategias para la prevención y la intervención. Oxford University Press.

Goodman, D. M., Walling, S., \& Ghali, A. A. (2010). La psicología en busca de la justicia: la vida y obra de Emmanuel Levinas e Ignacio Martín-Baró. Pastoral Psychology, 59, 585-602. https://doi.org/10.1007/s11089-009-0260-4

Haimi, M. \& Lerner, A. (2016). El impacto de la separación y el divorcio de los padres en el estado de salud de los niños y formas de mejorarlo. Journal of Clinical \& Medical Genomics, 4(1). https://doi.org/10.4172/jcmg.1000137

Hall, E. T. (1976). Beyond Culture. Anchor Books.

Hall, E. T. (1990). Understanding Cultural Differences. Maine Intercultural Press Inc.

ImpactoGT. (2018, julio 25). Aumenta el número de suicidios en Nebaj, Quiche, existe preocupación. ImpactoGT. https://impacto.gt/aumenta-el-numero-de-suicidios-ennebajquiche/

Jaiswal, S. V., Faye, A. D., Gore, S. P., Shah, H. R. \& Kamath, R. M. (2016). Eventos estresantes de la vida, desesperanza e intención suicida en pacientes ingresados con intento de suicidio en un hospital general de atención terciaria. Journal of Postgraduate Medicine, 62(2), 102-104. https://doi.org/10.4103/o022-3859.180556

Klie, M. \& Grazioso, M. P. (2020). Current Context of the Teaching of Psychology in Guatemala. En G. J. Rich, L. A. Padilla Lopez, L. Ebersohn, J. Taylor, S. M. (Eds.). Teaching Psychology around the World (Vol. 5, pp. 70-88). Cambridge Scholars Publishing.

Klonsky, E. D. \& May, A. M. (2015). Impulsividad y riesgo de suicidio: revisión e implicaciones clínicas. Psychiatric Times, 32(8).

https://www.psychiatrictimes.com/impulsivity-and-suicide-risk-review-and-clinicalimplications.

Long, S. (2013, septiembre 12). Patrimonio cultural debajo de la línea de agua. Blog de OIC Moments. https://www.oh-i-see.com/blog/2013/o9/12/culture-smart-3s-and-4s/. 
Lizardi D., Thompson R. G., Keyes, K. \& Hasin, D. (2010). El papel de la depresión en el efecto diferencial del divorcio de los padres durante la infancia en el riesgo de intento de suicidio de hijos adultos masculinos y femeninos. Journal of Nervous and Mental Disease, 198, 687-690. https://doi.org/10.1097/NMD.ob013e3181ef218c

Manz, B. (2004). Paradise in ashes: A Guatemalan Journey of Courage, Terror, and Hope. University of California Press.

McCreery, D. (1983). Debt Servitude in Rural Guatemala, 1876-1936. Hispanic American Historical Review, 63(4), 735-759. https://doi.org/10.2307/2514903

Mueller, A. S. (2017). ¿̇Importan los medios al suicidio? Examinando la dinámica social que rodea a los medios que informan sobre el suicidio en una comunidad propensa al suicidio. Social Science \& Medicine, 180, 152-159. https://doi.org/10.1016/j.socscimed.2017.03.019

Nolin, C. (2018). Memory, Truth, Justice: The Crisis of the Living in the Search for Guatemala's Dead and Disappeared. En S. Henigan y C. Johnson (Eds.), Human and environmental justice in Guatemala (pp. 34-55). University of Toronto Press. https://doi.org/10.3138/9781487519001-004

OMS. (2014, mayo 10). Preventing Suicide: A Global Imperative. WHO. https://www.who.int/mental_health/suicide-prevention/world_report_2014/en/.

OPS. (2014). Mortalidad por suicidio en las Américas: Informe regional. Organización Panamericana de la Salud. https://www.paho.org/hq/dmdocuments/2014/PAHO-mortalitysuicide--final.pdf.

PNUD. (2016). Más allá del conflicto, luchas por el bienestar. Informe Nacional de Desarrollo Humano 2015/2016. Guatemala City: Programa de las Naciones Unidas para el Desarrollo (PNUD).

Prensa Libre. (2018, septiembre 23). Urge restaurar tejido social. Prensa Libre. https://www.pressreader.com/guatemala/prensa-libre/20180923/281767040143397

Pritchard, C. \& Hean, S. (2008). Suicidio y muertes indeterminadas entre jóvenes y adultos jóvenes en América Latina: Comparación con los 10 principales países desarrollados: ¿una fuente de suicidios ocultos? Crisis, 29(3), 145-153. https://doi.org/10.1027/0227$5910.29 \cdot 3.145$

Rajalin, M. \& Salander Renberg, E. (2017). Antecedentes familiares de suicidio y funcionamiento interpersonal en personas que intentan suicidarse. Psychiatry Research, 247, 310-314. https://doi.org/10.1016/j.psychres.2016.11.029 
Reed, K. P., Nugent, W. \& Cooper R. L. (2015). Probando un modelo de ruta de relaciones entre género, edad y victimización por bullying y comportamiento violento, abuso de sustancias, depresión, ideación suicida e intentos de suicidio en adolescentes. Children and Youth Services Review, 55, 128-137. https://doi.org/10.1016/j.childyouth.2015.05.016

Rogers, M. L. \& Joiner, T. E. (2018). Suicide-specific rumination relates to lifetime suicide attempts above and beyond a variety of other suicide risk factors. Journal of Psychiatric Research, 98, 78-86. https://doi.org/10.1016/j.jpsychires.2017.12.017

Rothenberg, D. (2012). Memory of silence: The Guatemalan Truth Commission report. Palgrave Macmillan. https://link.springer.com/content/pdf/bfm\%3A978-1-137-01114$5 \% 2 \mathrm{~F} 1 . p d f$

Rubenstein, J. L., Halton, A., Kasten, L. \& Stechler, G. (1998). Comportamiento suicida en adolescentes: estrés y protección en diferentes contextos familiares. American Journal of Orthopsychiatry, 68(2), 274-84. https://doi.org/10.1037/hoo80336

Sawaia, B. B. (2009). Psicologia e desigualdade social: uma reflexão sobre liberdade e tranformação social. Psicologia \& Sociedade, 21(3), 364-372. https://doi.org/10.1590/So10271822009000300010

Stack, A. \& Scourfield, J. (2013). Divorcio reciente, la depresión y el riesgo de suicidio. Journal of Family Issues, 36(6). https://doi.org/10.1177/0192513X13494824

Turecki, G. \& Brent, D. A. (2016). Suicidio y comportamiento suicida. Lancet, 387(10024), 1227-1239. https://doi.org/10.1016/So140-6736(15)00234-2

World Life Expectancy (2021, August 25). Guatemala: Suicide. https://www.worldlifeexpectancy.com/guatemala-suicide

Zalsman, G., Hawton, K., Wasserman, D., van Heeringen, K. et al. (2016). Estrategias de prevención del suicidio retomadas: revisión sistemática de 10 años. Lancet Psychiatry. http://dx.doi.org/10.1016/S2215-0366(16)30030-X 